\title{
Optimization of cutting conditions of YG15 on rough and finish cutting in WEDM based on statistical analyses
}

\author{
Yu Huang • Wuyi Ming • Jianwen Guo • Zhen Zhang • \\ Guangdou Liu • Mingzhen Li • Guojun Zhang
}

Received: 9 November 2012 / Accepted: 29 April 2013 / Published online: 9 June 2013

(C) The Author(s) 2013. This article is published with open access at Springerlink.com

\begin{abstract}
In this paper, the effects and the optimization of cutting parameters on surface roughness $(\mathrm{Ra})$ and material removal rate (MRR) in the wire electrical discharge machining (WEDM) of high hardness tool steel YG15 are analyzed. In the WEDM process, the key process parameters, such as pulse-on time, pulse-off time, power, cutting feed rate, wire tension, wire speed, and water pressure, are optimized. Experimental data were initially collected based on the Taguchi method of experimental design, which are $L_{18}\left(2^{1} \times 3^{5}\right)$ and $L_{18}\left(2^{1} \times 3^{4}\right)$ Taguchi standard orthogonal array on rough and finish cutting experiments, respectively. The level of importance of the cutting parameters on the Ra and MRR was determined on both finish and rough cutting by using statistical analyses; average gap voltage is discussed in order to balance cutting efficiency and stability on both finish and rough cutting. In addition, comparative analysis of finish and rough cutting is drawn to analyze the difference between rough cutting and finish cutting. Then, regression models and signal-to-noise ratio are used to obtain the optimum cutting parameter combination. Finally, the results present the optimized MRR and Ra of the rough and finish process, respectively, and confirm the efficiency and abilities of the model.
\end{abstract}

Y. Huang $\cdot$ W. Ming $\cdot$ J. Guo $\cdot$ Z. Zhang $\cdot$ G. Liu $\cdot$ M. Li $\cdot$

G. Zhang $(\bowtie)$

State Key Lab of Digital Manufacturing Equipment \& Tech, School of Mechanical Science and Engineering, Huazhong University of Science \& Technology, Wuhan 430074, China e-mail: zhanggj.hust@gmail.com

Y. Huang

e-mail: yuhuang.hust@gmail.com

G. Zhang

Guangdong Province Key Lab of Digital Manufacturing

Equipment, Dongguan 523000, China
Keywords Wire cut - Optimization - Statistical analyses · Surface roughness $\cdot$ Material removal rate $\cdot$ Average gap voltage

\section{Introduction}

Wire electrical discharge machining (WEDM) is one of dominant machining processes for difficult-to-machine materials, which are widely used in tooling, especially in the cutlery and mold industry. The machining process removes the workpiece material by a series of electrical sparks, which generate discharge craters and recast layers on the surface of the workpiece, between the wire electrode and the workpiece. Yang and Guo [1] visualized the forming process of discharge craters in three dimensions with relatively small discharge energy and clarified the mechanism of material removal and formation of discharge crater shapes. Unsuitable electrical parameters can cause short circuits, low material removal rate (MRR), and high surface roughness $(\mathrm{Ra})$. It can be drawn from the pervious study in electrical discharge machining (EDM) [2-5]. Therefore, the parameters must be precisely optimized to maximize the process efficiency [6]. Qu and Shih [7] evaluated the surface integrity and roundness of cylindrical WEDM parts by proposing a mathematical model, which investigated the surface integrity and roundness of WEDM parts and explored a few ways to optimize process parameters in order to achieve better surface integrity and roundness.

The surface roughness of 1040 steel, 2379 steel, and 2738 steel was investigated by 2D graph analysis, which studied the effect of parameters of voltage, current, time of cutting, and average feed [8]. Liao and Gatto studied the effects of cutting settings on the behavior of pulse trains for tool steels [9] and the cutting mechanisms for metal matrix 

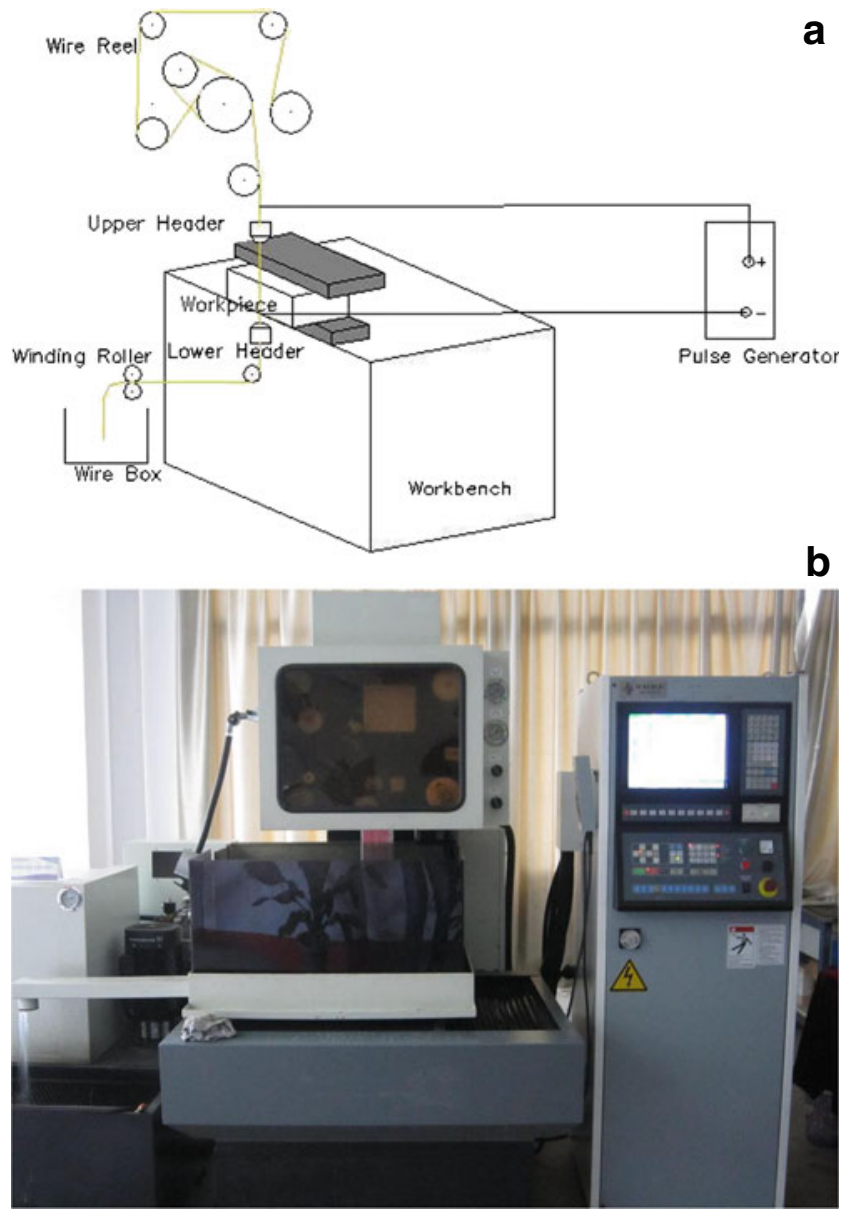

Fig. 1 The experimental equipment

ceramic composites [10]. Manna [11] established mathematical models, which were used in the Gauss elimination method for the WEDM machining, relating to the machining performance in order to analyze and improve the surface roughness. In order to predict the performance of MRR and Ra, Ramakrishnan and Karunamoorthy [12] and Kung and Chiang [13] developed a mathematical model using the
Table 1 Physical properties of the YG15 steel

\begin{tabular}{ll}
\hline Properties & Value \\
\hline Density $\left(\mathrm{g} / \mathrm{cm}^{3}\right)$ & 13.9 \\
Hardness (HRA) & $87 \sim 90$ \\
Bending strength $\left(\mathrm{N} / \mathrm{mm}^{2}\right)$ & 2,250 \\
Average particle $(\mathrm{nm})$ & 1.5 \\
Coefficient of expansion $\left({ }^{\circ} \mathrm{C}^{-1}\right)$ & $5.3 \times 10^{-6}$ \\
\hline
\end{tabular}

response surface methodology. The Taguchi's robust design approach was proposed for the WEDM operation in order to optimize the MRR and $\operatorname{Ra}[14,15]$. Mohammadi and Aminollah also used the Taguchi's method analysis of variance (ANOVA) to study the relationship between WEDM input and output measures [15, 16], and other scholars also used this method to investigate surface modification in EDM [17]. The artificial neural network was utilized to establish a mathematical relationship between the cutting parameters and output measures [18, 19]. It can be seen from above that the MRR and Ra are the most widely characteristics that are used to describe WEDM cutting conditions [6-13, 15-18].

In terms of workpiece material, tool steel YG15 was used because of its wide application in cutting tools and mold industry. Moreover, there is no record of any previous investigations on this material at cutting optimal parameters. In addition, there are few technical papers to study the difference of optimization of cutting conditions on rough and finish cutting in WEDM. Therefore, this study investigates the MRR and Ra via the WEDM cutting process of tool steel YG15 and finds possible ways to optimize its parameters to achieve better MRR and Ra on rough and finish cutting, respectively, under the suitable average gap voltage (AGV).

Experiments are employed in this study in order to optimize the parameters, which include pulse-on time, pulse-off time, power, cutting feed rate, wire tension, wire speed, and water pressure. A proper design of experiments (DOE)
Fig. 2 The waveform of the plus generator

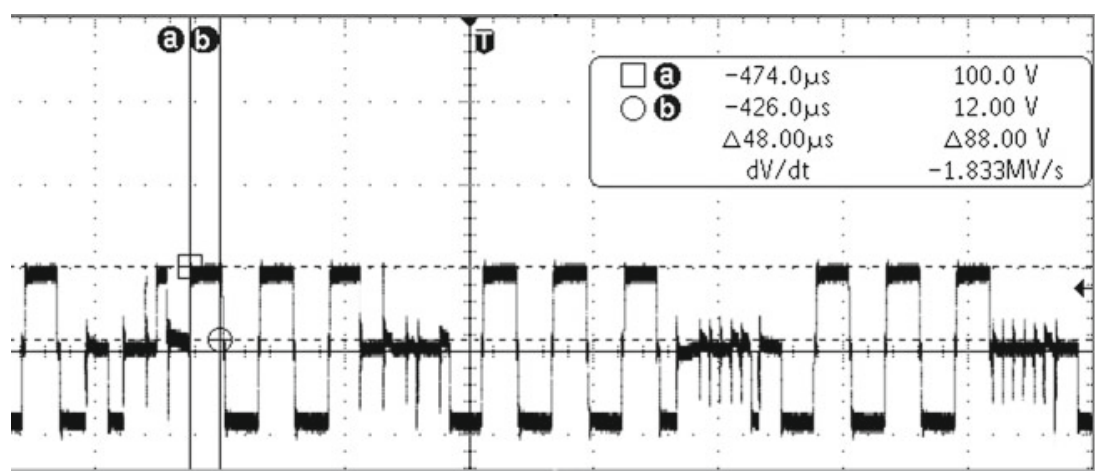




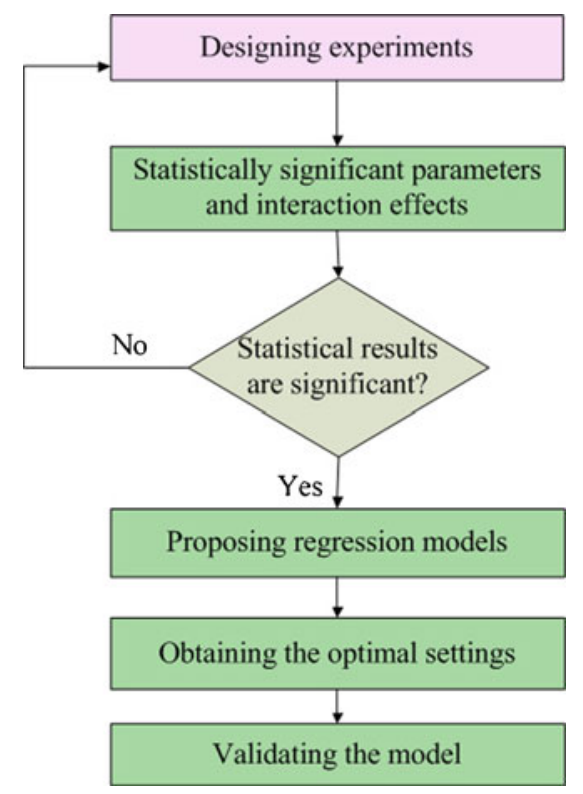

Fig. 3 The flowchart of WEDM cutting parameter's optimization

is needed to perform more accurate and more efficient experiments. Taguchi's technique has been widely used in DOE in the present research, and it is employed to perform the experimental design $[20,21]$. In this paper, three different analyses are discussed on the experimental data. Firstly, statistical analyses are applied to determine significant parameters and interaction of them for rough and finish cutting, respectively [22]. Secondly, regression models are proposed to establish a relationship between the parameters and responses. Thirdly, signal-to-noise $(\mathrm{S} / \mathrm{N})$ ratio analysis is studied in order to get the optimal settings of cutting parameters on rough and finish cutting respectively under suitable AGV [23].
Table 3 Fixed factors in the experimentation on rough and finish cutting

\begin{tabular}{lll}
\hline Parameter & $\begin{array}{l}\text { Value } \\
\text { on rough cutting }\end{array}$ & $\begin{array}{l}\text { Value } \\
\text { on finish cutting }\end{array}$ \\
\hline Depth of cut (mm) & 0.05 & 0.02 \\
Material & Tool steel YG15 & Tool steel YG15 \\
Thickness of specimens (mm) & 40 & 40 \\
Workpiece hardness (HRA) & $87 \sim 90$ & $87 \sim 90$ \\
Angle of cut & Vertical & Vertical \\
Dielectric temperature & $25^{\circ} \mathrm{C}$ & $25^{\circ} \mathrm{C}$ \\
Cutting length (mm) & 10 & 4 \\
Power (A) & 10 & - \\
Wire tension (Kgf) & - & 8 \\
Wire speed (m/min) & - & 4 \\
\hline
\end{tabular}

\section{Experimental setup, equipment and method}

In this research, the rough and finish cutting experiments are done by an W-A530 WEDM machine, which is made by Dongguan Hustinova Precision Machinery Co., Ltd. Figure 1 shows schematic drawing and photograph of the experimental equipment. The WEDM machine is equipped with anti-electrolysis plus generator, of which average voltage is 0 to prevent oxidation of the workpiece. Figure 2 depicts the waveform of the plus generator. The experiments are aimed at optimizing the effect of cutting parameters on MRR and Ra under suitable AGV.

The workpiece is a 40-mm-thick block of YG15 steel (wc: $85 \%$, co: $15 \%$ ). Physical properties of the workpiece are given in Table 1. The material of cutting brass wire is $\mathrm{Cu}$ with a diameter of $0.25 \mathrm{~mm}$. Next, 5- to $10-\mathrm{mm}$-long through cuts are made on the test pieces according to the rough and finish cutting experiments, respectively, and the

Table 2 Factors and their level on rough and finish cutting

\begin{tabular}{|c|c|c|c|c|c|c|}
\hline \multirow[t]{2}{*}{ Factors } & \multicolumn{3}{|c|}{ On rough cutting } & \multicolumn{3}{|c|}{ On finish cutting } \\
\hline & 1 & 2 & 3 & 1 & 2 & 3 \\
\hline Pulse-on time (s): time of the discharge pulse duration of high level & 3 & 8 & 13 & 5 & 9 & 15 \\
\hline Pulse-off time (s): time interval between one discharge and the next & 10 & 20 & 35 & 1 & 5 & 10 \\
\hline Power (A): an average current between the wire and the workpiece & - & - & - & 1 & 3 & 5 \\
\hline Cutting feed rate $(\mathrm{mm} / \mathrm{min})$ : the maximum setting cutting speed & 1 & 2.5 & 4 & 0.3 & 0.5 & 0.9 \\
\hline Wire tension (Kgf): level of mechanical stress & 6 & 10 & 14 & - & - & - \\
\hline Wire speed $(\mathrm{m} / \mathrm{min}):$ the rate of wire moving & 3 & 4 & 6 & - & - & - \\
\hline Water pressure $\left(\mathrm{kg} / \mathrm{cm}^{2}\right)$ : the impact pressure of dielectric flow & 5 & 11 & - & 4 & 6 & - \\
\hline
\end{tabular}


Table 4 Experimental results on rough cutting

\begin{tabular}{|c|c|c|c|c|c|c|c|c|c|c|c|c|c|c|c|}
\hline \multirow[t]{2}{*}{ No. } & \multirow[t]{2}{*}{ P.O. } & \multirow[t]{2}{*}{ P.F. } & \multirow[t]{2}{*}{ C.F. } & \multirow[t]{2}{*}{ W.T. } & \multirow[t]{2}{*}{ W.S. } & \multirow[t]{2}{*}{ W.P. } & \multicolumn{3}{|c|}{$\mathrm{Ra}(\mu \mathrm{m})$} & \multicolumn{3}{|c|}{$\operatorname{MRR}\left(\mathrm{mm}^{2} / \min \right)$} & \multicolumn{3}{|c|}{ AGV (V) } \\
\hline & & & & & & & $1 \mathrm{st}$ & $2 n d$ & Av. & $1 \mathrm{st}$ & $2 \mathrm{nd}$ & Av. & $1 \mathrm{st}$ & 2nd & Av. \\
\hline 1 & 3 & 10 & 1 & 6 & 3 & 5 & 1.435 & 1.407 & 1.421 & 0.31 & 0.2 & 0.255 & 63 & 71.5 & 67.3 \\
\hline 2 & 8 & 10 & 2.5 & 10 & 4 & 5 & 2.745 & 2.73 & 2.738 & 1.26 & 2.08 & 1.67 & 62 & 69 & 65.5 \\
\hline 3 & 13 & 10 & 4 & 14 & 6 & 5 & 3.069 & 3.06 & 3.065 & 2.53 & 3.94 & 3.235 & 64 & 70.8 & 67.4 \\
\hline 4 & 8 & 20 & 1 & 6 & 4 & 5 & 2.937 & 3.015 & 2.976 & 1 & 0.98 & 0.99 & 70.1 & 72.1 & 71.1 \\
\hline 5 & 13 & 20 & 2.5 & 10 & 6 & 5 & 3.501 & 2.793 & 3.147 & 2.5 & 2.46 & 2.48 & 69.8 & 71.5 & 70.7 \\
\hline 6 & 3 & 20 & 4 & 14 & 3 & 5 & 1.286 & 0.981 & 1.134 & 0.1 & 0.09 & 0.095 & 72.5 & 73 & 72.8 \\
\hline 7 & 13 & 35 & 1 & 10 & 3 & 5 & 3.478 & 3.494 & 3.486 & 0.98 & 1 & 0.99 & 72 & 73 & 72.5 \\
\hline 8 & 3 & 35 & 2.5 & 14 & 4 & 5 & 1.186 & 0.626 & 0.906 & 0.05 & 0.01 & 0.03 & 75 & 78 & 76.5 \\
\hline 9 & 8 & 35 & 4 & 6 & 6 & 5 & 2.871 & 2.382 & 2.627 & 0.98 & 0.63 & 0.805 & 67.9 & 72 & 70 \\
\hline 10 & 8 & 10 & 1 & 14 & 6 & 11 & 2.954 & 2.694 & 2.824 & 0.98 & 1 & 0.99 & 74.3 & 72.5 & 73.4 \\
\hline 11 & 13 & 10 & 2.5 & 6 & 3 & 11 & 3.45 & 3.388 & 3.419 & 2.45 & 2.47 & 2.46 & 71 & 70.5 & 70.8 \\
\hline 12 & 3 & 10 & 4 & 10 & 4 & 11 & 1.28 & 1.27 & 1.275 & 0.22 & 0.19 & 0.205 & 69.7 & 70 & 69.9 \\
\hline 13 & 3 & 20 & 1 & 10 & 6 & 11 & 0.957 & 1.002 & 0.98 & 0.07 & 0.06 & 0.065 & 72.5 & 74 & 73.3 \\
\hline 14 & 8 & 20 & 2.5 & 14 & 3 & 11 & 2.54 & 2.641 & 2.591 & 1.41 & 1.43 & 1.42 & 61.8 & 64 & 62.9 \\
\hline 15 & 13 & 20 & 4 & 6 & 4 & 11 & 3.121 & 2.827 & 2.974 & 2.27 & 3 & 2.635 & 61.3 & 63 & 62.2 \\
\hline 16 & 13 & 35 & 1 & 14 & 4 & 11 & 3.37 & 3.209 & 3.29 & 1 & 0.98 & 0.99 & 67.2 & 70 & 68.6 \\
\hline 17 & 3 & 35 & 2.5 & 6 & 6 & 11 & 0.78 & 0.73 & 0.755 & 0.01 & 0.06 & 0.035 & 81 & 80 & 80.5 \\
\hline 18 & 8 & 35 & 4 & 10 & 3 & 11 & 2.853 & 2.663 & 2.758 & 0.85 & 0.15 & 0.5 & 61.5 & 65.5 & 63.5 \\
\hline
\end{tabular}

P.O. plus-on time, P.F. plus-off time, C.F. cutting feed rate, W.T. wire tension, W.S. wire speed, W.P. water pressure, Ra Surface roughness, MRR Material removal rate, $A G V$ Average gap voltage, $A v$. Average

Table 5 Experimental results on finish cutting

\begin{tabular}{|c|c|c|c|c|c|c|c|c|c|c|c|c|c|c|}
\hline \multirow[t]{2}{*}{ No. } & \multirow[t]{2}{*}{ P.O. } & \multirow[t]{2}{*}{ P.F. } & \multirow[t]{2}{*}{ Power } & \multirow[t]{2}{*}{ C.F. } & \multirow[t]{2}{*}{ W.P. } & \multicolumn{3}{|c|}{$\mathrm{Ra}(\mu \mathrm{m})$} & \multicolumn{3}{|c|}{$\operatorname{MRR}\left(\mathrm{mm}^{2} / \mathrm{min}\right)$} & \multicolumn{3}{|c|}{ AGV (V) } \\
\hline & & & & & & $1 \mathrm{st}$ & 2nd & Av. & $1 \mathrm{st}$ & 2nd & Av. & $1 \mathrm{st}$ & $2 \mathrm{nd}$ & Av. \\
\hline 1 & 5 & 1 & 1 & 0.3 & 4 & 0.398 & 0.356 & 0.377 & 0.292 & 0.292 & 0.292 & 70 & 60 & 65 \\
\hline 2 & 5 & 5 & 3 & 0.5 & 4 & 0.27 & 0.387 & 0.329 & 0.48 & 0.488 & 0.484 & 59 & 60 & 59.5 \\
\hline 3 & 5 & 10 & 5 & 0.9 & 4 & 0.695 & 0.26 & 0.478 & 0.93 & 0.922 & 0.926 & 65.1 & 62 & 63.6 \\
\hline 4 & 9 & 1 & 1 & 0.5 & 4 & 0.569 & 0.568 & 0.569 & 0.487 & 0.492 & 0.49 & 56.5 & 61 & 58.8 \\
\hline 5 & 9 & 5 & 3 & 0.9 & 4 & 0.294 & 0.321 & 0.308 & 0.639 & 0.823 & 0.731 & 50 & 55 & 52.5 \\
\hline 6 & 9 & 10 & 5 & 0.3 & 4 & 0.229 & 0.343 & 0.286 & 0.256 & 0.293 & 0.275 & 52 & 65 & 58.5 \\
\hline 7 & 15 & 1 & 3 & 0.3 & 4 & 0.285 & 0.385 & 0.335 & 0.174 & 0.295 & 0.235 & 48.5 & 55 & 51.8 \\
\hline 8 & 15 & 5 & 5 & 0.5 & 4 & 0.27 & 0.401 & 0.336 & 0.446 & 0.491 & 0.469 & 46 & 46 & 46 \\
\hline 9 & 15 & 10 & 1 & 0.9 & 4 & 0.522 & 0.534 & 0.528 & 0.877 & 0.858 & 0.868 & 56 & 61 & 58.5 \\
\hline 10 & 5 & 1 & 5 & 0.9 & 6 & 0.295 & 0.368 & 0.332 & 0.6 & 0.862 & 0.731 & 41.5 & 66 & 53.8 \\
\hline 11 & 5 & 5 & 1 & 0.3 & 6 & 0.31 & 0.29 & 0.3 & 0.291 & 0.295 & 0.293 & 60 & 70 & 65 \\
\hline 12 & 5 & 10 & 3 & 0.5 & 6 & 0.215 & 0.288 & 0.252 & 0.338 & 0.474 & 0.406 & 45 & 55 & 50 \\
\hline 13 & 9 & 1 & 3 & 0.9 & 6 & 0.275 & 0.268 & 0.272 & 0.226 & 0.576 & 0.401 & 39 & 43 & 41 \\
\hline 14 & 9 & 5 & 5 & 0.3 & 6 & 0.228 & 0.195 & 0.212 & 0.29 & 0.293 & 0.292 & 45 & 50 & 47.5 \\
\hline 15 & 9 & 10 & 1 & 0.5 & 6 & 0.41 & 0.462 & 0.436 & 0.487 & 0.492 & 0.49 & 58.5 & 58 & 58.3 \\
\hline 16 & 15 & 1 & 5 & 0.5 & 6 & 0.27 & 0.253 & 0.262 & 0.437 & 0.293 & 0.37 & 41.5 & 43.5 & 42.5 \\
\hline 17 & 15 & 5 & 1 & 0.9 & 6 & 0.381 & 0.832 & 0.607 & 0.111 & 0.303 & 0.207 & 43 & 46 & 44.5 \\
\hline 18 & 15 & 10 & 3 & 0.3 & 6 & 0.238 & 0.225 & 0.232 & 0.238 & 0.207 & 0.223 & 47 & 45 & 46 \\
\hline
\end{tabular}

P.O. plus-on time, P.F. plus-off time, C.F. cutting feed rate, W.P. water pressure, Ra Surface roughness, $M R R$ Material removal rate, $A G V$ Average gap voltage, $A v$. Average 
Fig. 4 Main effect of factors on surface roughness $(R a)$ (in micrometers) and MRR (in square millimeters per minute) on rough cutting
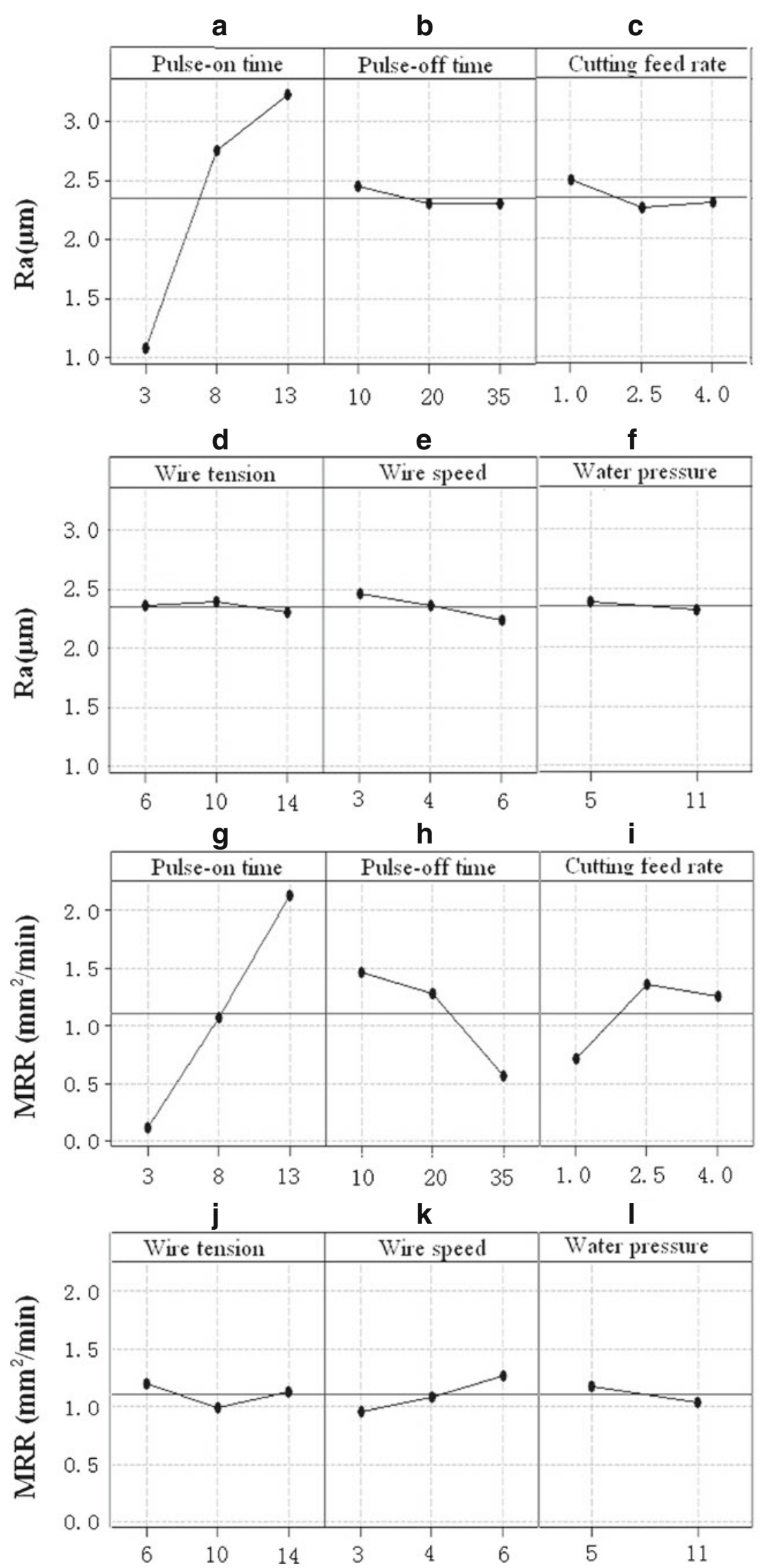
cutting time is measured by a stopwatch. Then, the MRR is calculated with the following equations ( 1 and 2):

$F_{r}=\frac{60 \times l}{t}$

$$
M R R=F_{r} \times H
$$

where $F_{r}$ is the average feed rate in millimeters per minute, $l$ is the cutting length in millimeters, and $t$ is the cutting time is seconds. $H$ is the workpiece thickness in millimeters, and MRR is thus measured in square millimeter per minute. When the cutting was complete, the surface finish was measured on a roughness-measuring machine (Taylor-Hobson, talysurf 5-120) for three times on the same position. The final reported roughness $\mathrm{Ra}$ (in micrometers) of each sample was the average of these three measurements.

This research is based on statistical analyses. The Taguchi approach to laying out experimental conditions significantly reduces the number of tests, overall testing time, and cost of experiments. The experimental data are initially collected based on the Taguchi method of experimental design, which are $L_{18}\left(2^{1} \times 3^{5}\right)$ and $L_{18}\left(2^{1} \times 3^{4}\right)$ Taguchi standard orthogonal array on rough cutting and finish cutting experiments, respectively. Then, regression models and $\mathrm{S} / \mathrm{N}$ method are utilized to analyze the experimental data. From these, the optional cutting parameters will be obtained.Then, the model is validated by confirmation experiments. Figure 3 illustrates the optimization procedures implemented in this research.
Table 6 Main effect of factors on Ra (in micrometers) on rough cutting

\begin{tabular}{lll}
\hline Factors & Factor effects & $\begin{array}{l}\text { Relatively factor } \\
\text { effects }(\%)\end{array}$ \\
\hline Pulse-on time $(\mu \mathrm{s})$ & 2.152 & 73.03 \\
Pulse-off time $(\mu \mathrm{s})$ & 0.157 & 5.32 \\
Cutting feed rate $(\mathrm{mm} / \mathrm{min})$ & 0.237 & 8.04 \\
Wire tension $(\mathrm{Kgf})$ & 0.096 & 3.26 \\
Wire speed $(\mathrm{m} / \mathrm{min})$ & 0.235 & 7.97 \\
Water pressure $\left(\mathrm{kg} / \mathrm{cm}^{2}\right)$ & 0.070 & 2.38 \\
\hline
\end{tabular}

\section{Design of experiment}

The experiments include rough and finish cutting experiments. The factors and the levels are shown in Table 2. Since the current cannot be set on rough cutting in the machine, the constant current value is $10 \mathrm{~A}$. For rough cutting experiments, pulse-on time, pulse-off time, cutting feed rate, wire tension, wire speed, and water pressure are selected as independent variables which vary during the rough cutting experiments. Three levels or two levels (for water pressure factor) are adopted and set during the experiments by the DOE for the six factors. By factorial experiment, the effect of wire tension and wire speed can be omitted in finish cutting. For finish cutting experiments, pulse-on time, pulse-off time, current, cutting feed rate, and water pressure
Fig. 5 Interaction effect on rough cutting: (a) pulse-on time and pulse-off time on surface roughness $(R a)$ (in micrometers); (b) water pressure and wire tension on surface roughness $(R a)$ (in micrometers); (c) pulse-on time and pulse-off time on MRR (in square millimeters per minute); (d) water pressure and wire tension on MRR (in square millimeters per minute)
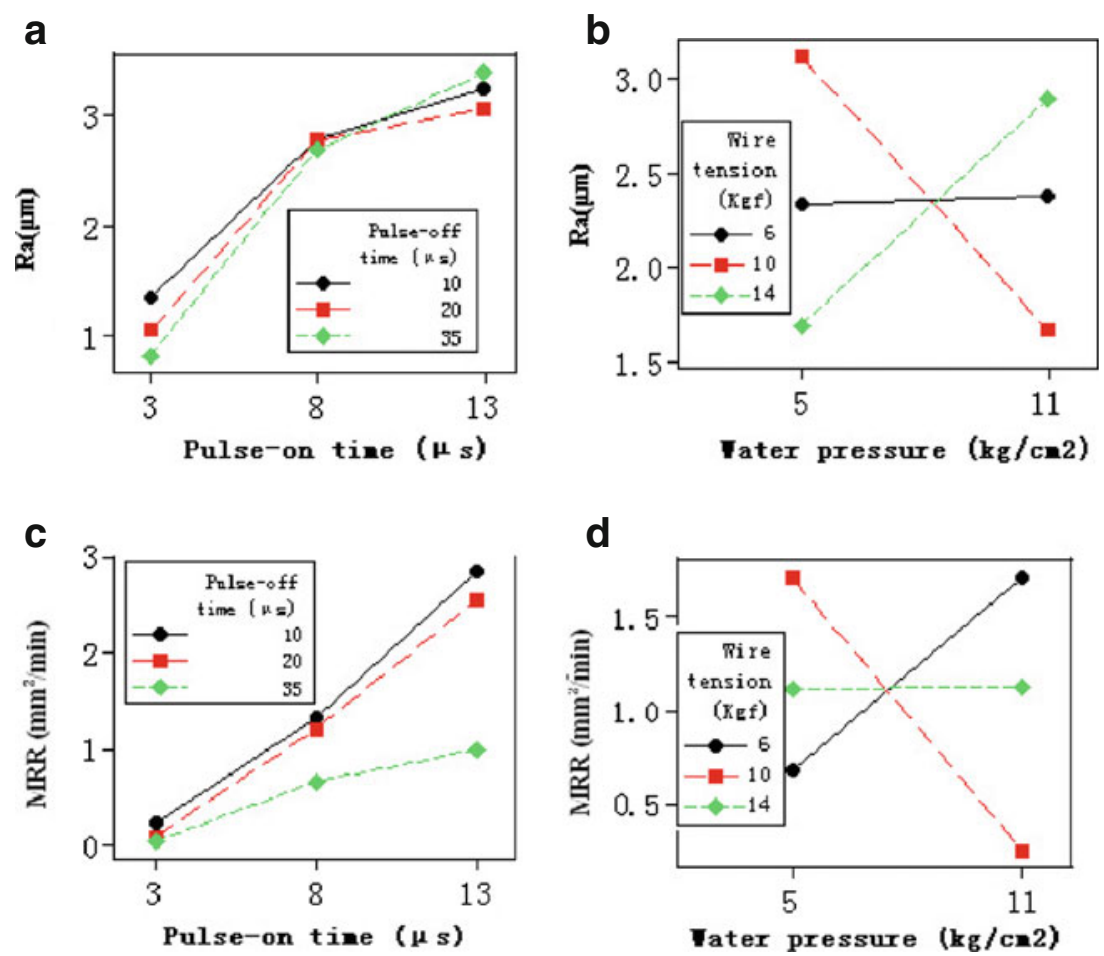
Table 7 Main effect of factors on MRR (in square millimeters per minute) on rough cutting

\begin{tabular}{lll}
\hline Factors & Factor effects & $\begin{array}{l}\text { Relatively factor } \\
\text { effects }(\%)\end{array}$ \\
\hline Pulse-on time $(\mu \mathrm{s})$ & 2.0175 & 47.70 \\
Pulse-off time $(\mu \mathrm{s})$ & 0.9108 & 21.53 \\
Cutting feed rate $(\mathrm{mm} / \mathrm{min})$ & 0.6358 & 15.03 \\
Wire tension $(\mathrm{Kgf})$ & 0.2117 & 5.01 \\
Wire speed $(\mathrm{m} / \mathrm{min})$ & 0.3150 & 7.45 \\
Water pressure $\left(\mathrm{kg} / \mathrm{cm}^{2}\right)$ & 0.1389 & 3.28 \\
\hline
\end{tabular}

are selected. Three levels or two levels (for water pressure factor) are adopted and set during the experiments by the DOE for the five factors.

Some factors do not change during the experiments, because of the WEDM setup. These fixed factors are presented in Table 3. In this research, only the main effects of factors and their interactions are of interest. Therefore, $L_{18}\left(2^{1} \times 3^{5}\right)$ and $L_{18}\left(2^{1} \times 3^{4}\right)$ Taguchi standard orthogonal array are selected on rough and finish cutting experiments respectively.

\section{Experimental results and data analysis}

In this section, four subsections are included. Firstly, the experimental results are shown in Section 4.1. Secondly, data analysis of the rough cutting on Ra and on MRR are depicted by statistical analyses in Section 4.2. Thirdly, data analysis of the finish cutting on Ra and on MRR are depicted also by statistical analyses in Section 4.3. The lastly, comparative analysis of the finish cutting and the rough cutting is drawn in Section 4.4.

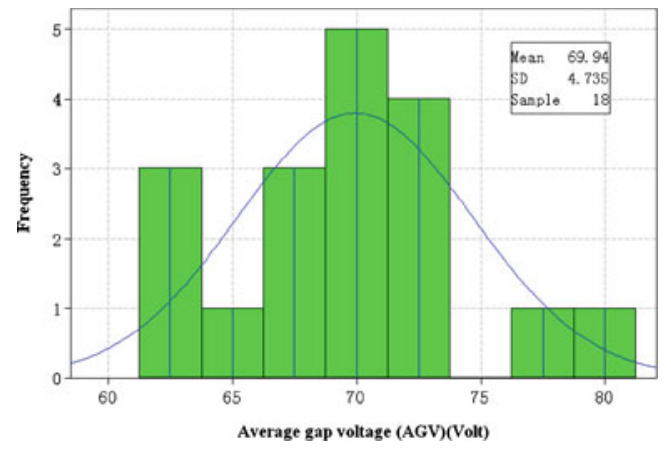

Fig. 6 Statistical histogram of AGV (in volts) on rough cutting ( $S D$ : Standard Deviation)

\subsection{Experimental results}

Table 4 shows the rough cutting response data acquired for Ra, MRR, and AGV by $L_{18}\left(2^{1} \times 3^{5}\right)$ Taguchi standard orthogonal array, and Table 5 shows the finish cutting response data acquired for Ra, MRR, and AGV by $L_{18}\left(2^{1} \times 3^{4}\right)$ Taguchi standard orthogonal array. It is noted that the run orders of both experiments are selected randomly.

\subsection{Data analysis of rough cutting}

In this research, Minitab 16 statistical software is utilized for data analysis. Figure $4 \mathrm{a}-\mathrm{f}$ draws the main effect of factors on $\mathrm{Ra}$ for the rough cutting. It is note that the data mean is utilized to determine factor effects. With this figure, the factor effects can be visually observed. Figure 4a illustrates the effect of pulse-on time on Ra. It shows that pulse-on time has the extremely important effect on Ra. In addition, there is a clear linear relationship between pulse-on time and surface roughness; the surface roughness increases significantly by increasing pulse-on time. Figure $4 b-f$ show the effect of pulse-off time, cutting feed rate, wire tension, wire speed, and water pressure on the surface roughness. As it is depicted, none of the factors have an extremely important effect on Ra except cutting feed rate and wire speed. The main effects are calculated and shown in Table 6. In statistical analyses, the factor effect is defined as the difference between the two extreme values of the response obtained for the corresponding factor [22]; and the relatively factor effect is defined as Eq. 3, where $R E_{i}$ is the $i_{t h}$ relatively factor effect, and $E_{i}$ is the $i_{t h}$ factor effect. The graphical assessment also can be depicted from Table 6 .

$R E_{i}=\frac{E_{i}}{\sum_{j=1}^{n} E_{j}}$

Yang and Guo [1] visualized the forming process of discharge craters and discussed the effect of electrical parameters on discharge craters. These parameters have significant effect on processing. In addition, the literature [6-9] also describe the similar regularity. In this research, pulse-on time and pulse-off time account for $78.35 \%$ in the whole factor effects on Ra. Figure 5a shows pulse-on time and pulse-off time interaction effect on Ra. This figure shows that there are differences of the slope of the pulseon time $(3,8$, and $13 \mu \mathrm{s})$ and the pulse-off time $(10,20$, and $35 \mu \mathrm{s})$. Therefore, it can be drawn that there is an interaction between pulse-on time and pulse-off time on $\mathrm{Ra}$. For example, when pulse-on time is $13 \mu \mathrm{s}$, the good Ra can be achieved by setting pulse-off time $20 \mu$ s (not $35 \mu \mathrm{s})$. The same procedure is also used for the interaction between water pressure and wire tension on $\mathrm{Ra}$, and there is 
Fig. 7 Main effect of factors on surface roughness $(R a)$ (in micrometers) and MRR (in square millimeter per minute) on finish cutting
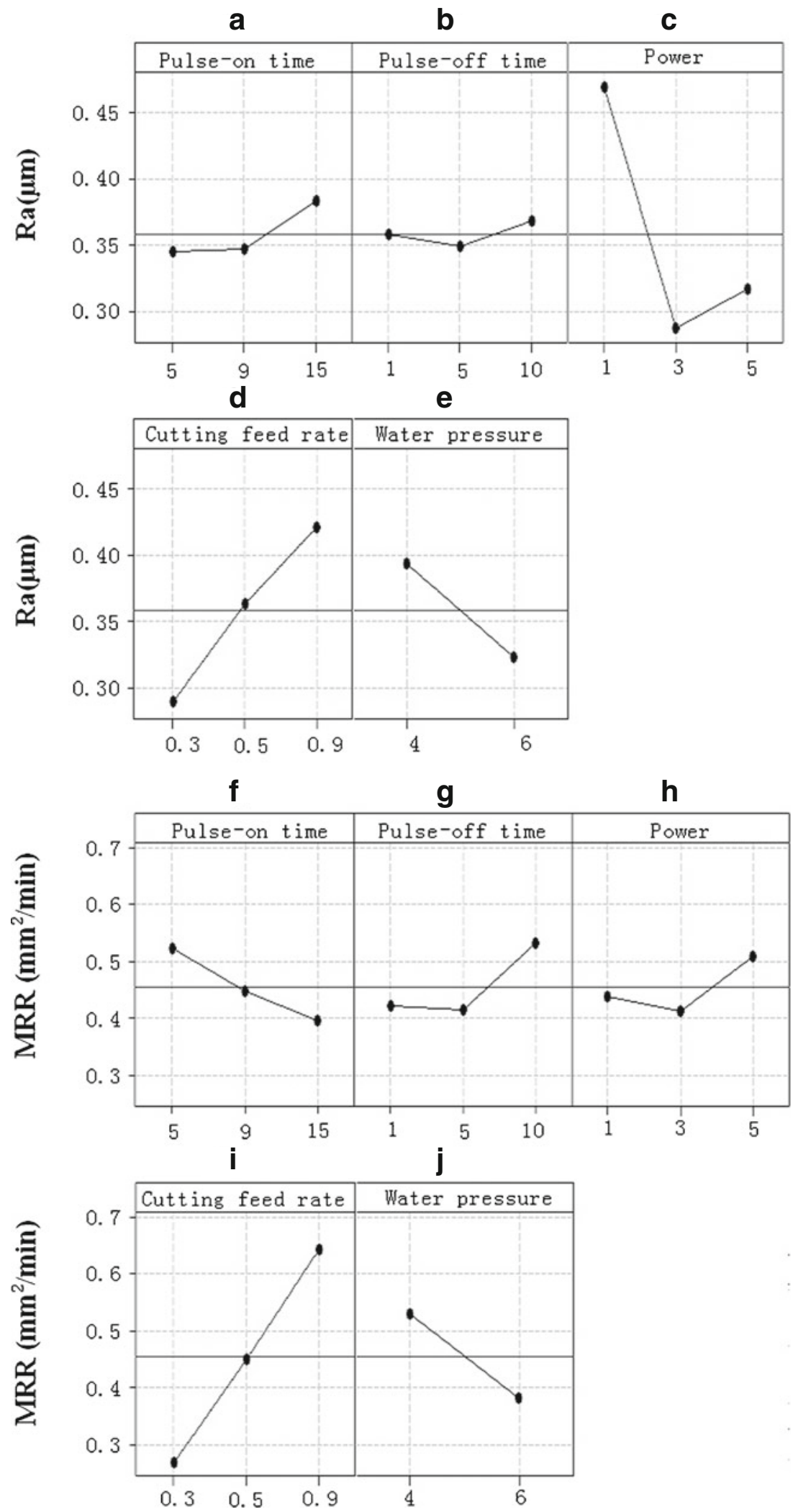

The same procedure is used for MRR. Figure $4 \mathrm{~g}-1$ shows that the effects of pulse-on time, pulse-off time, and cutting feed rate are also important than other factors. The 
Table 8 Main effect of factors on Ra (in micrometers) on finish cutting

\begin{tabular}{lll}
\hline Factors & $\begin{array}{l}\text { Factor } \\
\text { effects }\end{array}$ & $\begin{array}{l}\text { Relatively factor } \\
\text { effects }(\%)\end{array}$ \\
\hline Pulse-on time $(\mu \mathrm{s})$ & 0.0387 & 8.76 \\
Pulse-off time $(\mu \mathrm{s})$ & 0.02 & 4.53 \\
Power $(\mathrm{A})$ & 0.1815 & 41.07 \\
Cutting feed rate $(\mathrm{mm} / \mathrm{min})$ & 0.1305 & 29.53 \\
Water pressure $\left(\mathrm{kg} / \mathrm{cm}^{2}\right)$ & 0.0712 & 16.11 \\
\hline
\end{tabular}

Table 9 Main effect of factors on MRR (in square millimeters per minute) on finish cutting

\begin{tabular}{lll} 
Factors & Factor effects & $\begin{array}{l}\text { Relatively factor } \\
\text { effects }(\%)\end{array}$ \\
\hline Pulse-on time $(\mu \mathrm{s})$ & 0.1267 & 14.58 \\
Pulse-off time $(\mu \mathrm{s})$ & 0.1187 & 13.66 \\
Power $(\mathrm{A})$ & 0.0972 & 11.18 \\
Cutting feed rate $(\mathrm{mm} / \mathrm{min})$ & 0.3757 & 43.23 \\
Water pressure $\left(\mathrm{kg} / \mathrm{cm}^{2}\right)$ & 0.1508 & 17.35 \\
\hline
\end{tabular}

Fig. 8 Interaction effect on finish cutting: (a) pulse-on time and pulse-off time on surface roughness $(R a)$ (in micrometers); (b) water pressure and pulse-on on surface roughness $(R a)$ (in micrometers); (c) water pressure and pulse-off on surface roughness $(R a)$ (in micrometers); (d) water pressure and power on surface roughness $(R a)$ (in micrometers); (e) pulse-on time and pulse-off time on MRR (in square millimeters per minute); (f) water pressure and pulse-on on MRR (in square millimeters per minute); (g) water pressure and pulse-off on MRR (in square millimeters per minute); (h) water pressure and power on MRR (in square millimeters per minute) a
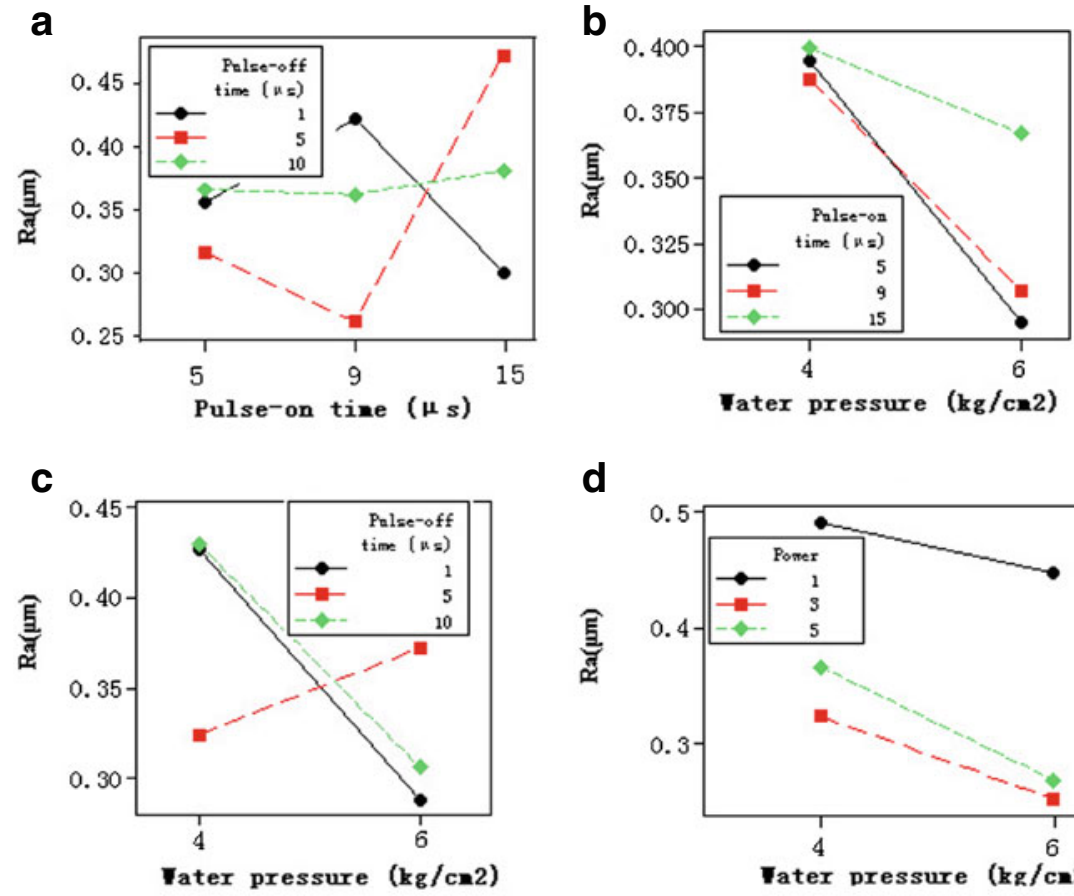

d
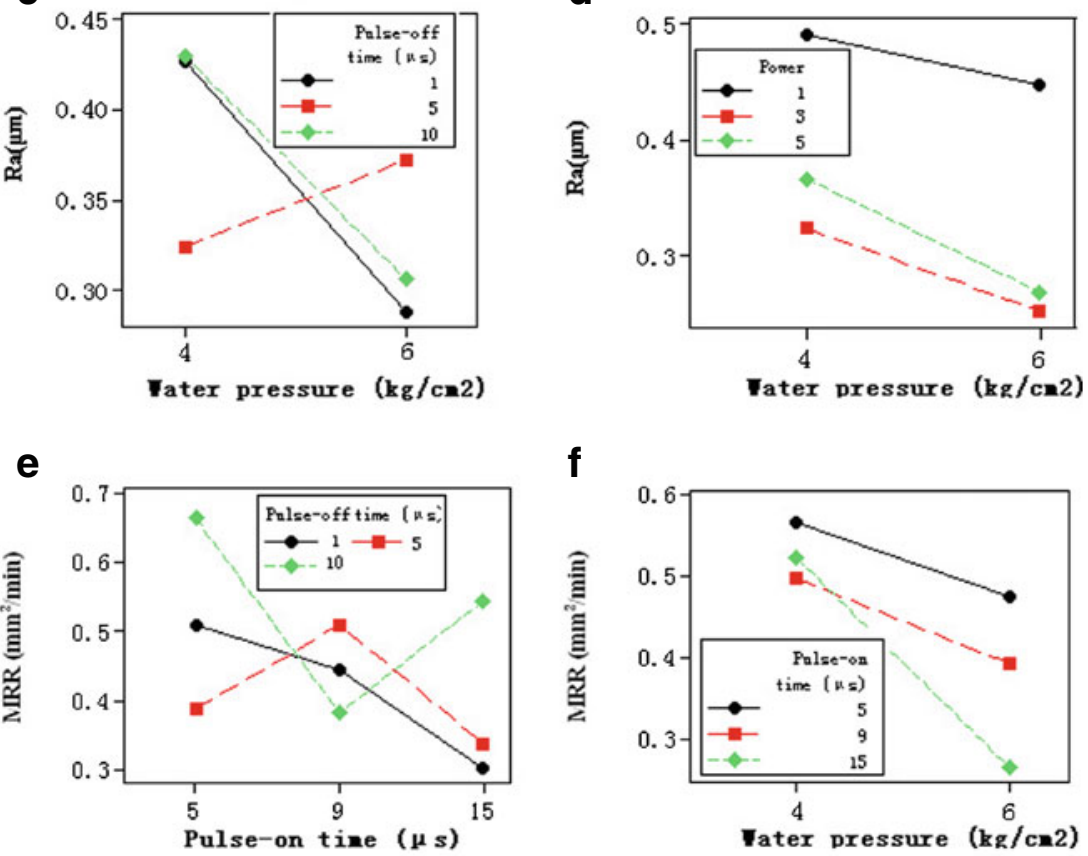

f

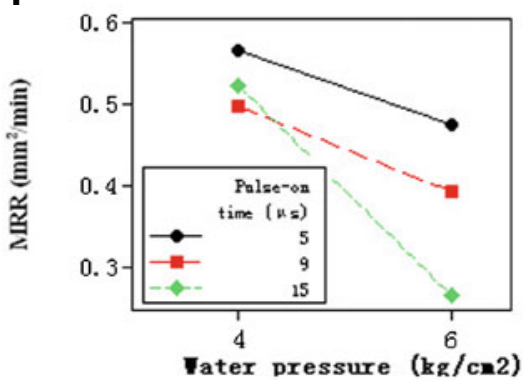

h

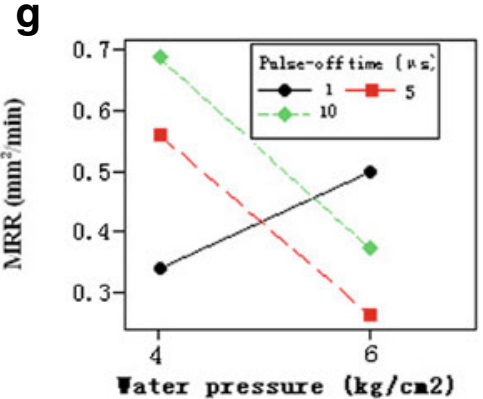

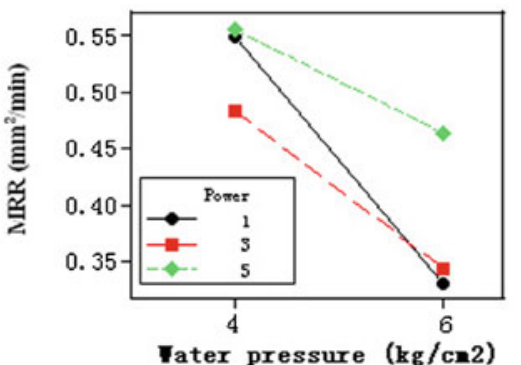




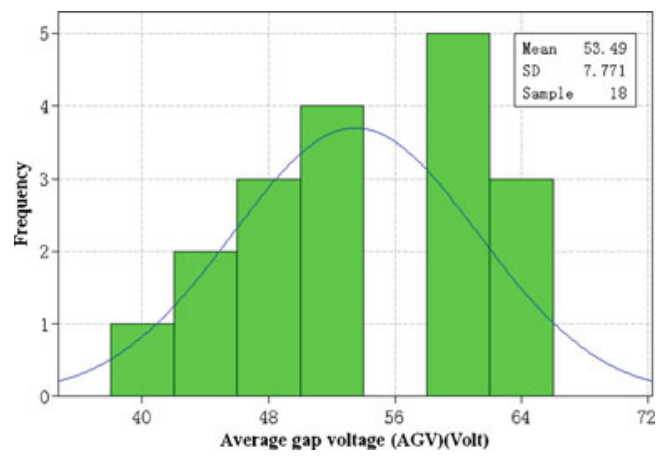

Fig. 9 Statistical histogram of AGV (in volts) on finish cutting ( $S D$ : Standard Deviation)

same conclusion can be drawn using Table 7. The factor effects are listed in this Table. Figure $5 \mathrm{c}-\mathrm{d}$ depict interaction effect on MRR. Similarly, there are interaction effect between pulse-on time and pulse-off time and also between water pressure and wire tension on MRR.

In WEDM process, there are generally four types of discharge, namely, arcs, open circuit, short circuit, and normal discharge. For the WEDM in this research, the arc voltage is lower than $35 \mathrm{~V}$; the open circuit voltage is higher than $85 \mathrm{~V}$; and the normal discharge voltage is at between 35 and $85 \mathrm{~V}$. In normal discharge, high voltage means that the machine efficiency is not high; low voltage shows the unstable status of processing. Therefore, gap voltage need to be monitored in the process. The average gap voltage can be calculated by sampling gap voltage every $3 \mathrm{~s}$ in the whole process.

Figure 6 shows statistical histogram of AGV on rough cutting. It can be seen from Fig. 6 that the mean of AGV is $69.94 \mathrm{~V}$. Most of the AGV exist between 65 and $74 \mathrm{~V}$. It can be concluded that the status of the cutting is normal. For the two experiments (nos. 8 and 17 in Table 4), AGV are more than $75 \mathrm{~V}$ and the machine utilization is not high. This can be verified from the MRR data in Table 4. High AGV causes the small cutting current, leading to lower MRR.

\subsection{Data analysis of finish cutting}

Figure 7a-e draws the main effect of factors on Ra on finish cutting. Figure $7 \mathrm{c}$, d illustrates the effect of power and cutting feed rate on Ra, respectively. It shows that power and cutting feed rate have the extremely important effect on Ra. In addition, there is a clear linear relationship in cutting feed rate and $\mathrm{Ra}$; the Ra increases significantly by increasing cutting feed rate. However, cutting feed rate fell sharply and then recover slowly during increasing power. Figure $7 \mathrm{a}, \mathrm{b}$, e shows the effect of pulse-on time, pulse-off time, and water pressure on the Ra. As it is depicted, none of the factors have an extremely important effect on Ra except water pressure. The main effects are calculated and shown in Table 8.

Figure 8a shows pulse-on time and pulse-off time interaction effect on Ra. This figure shows that the slope of the pulse-on time $(5,9$, and $15 \mu \mathrm{s})$ and the pulse-off time (1, 5 , and $10 \mu \mathrm{s}$ ) are different. Therefore, it can be drawn that there is an interaction between pulse-on time and pulse-off time on Ra. Similarly, there are interaction effect between water pressure and pulse-on time, between water pressure and pulse-off time, and between water pressure and power on Ra.

The same procedure is used for MRR. Figure $7 f, i, j$ shows that the effects of pulse-on time, cutting feed rate, and water pressure are more important than other factors. The same conclusion can be drawn using Table 9. The factor effects are listed in this Table. Figure 8e-h depicts interaction effect on MRR. Similarly, there are interaction effect between pulse-on time and pulse-off time, between water pressure and pulse-on time, between water pressure and pulse-off time, and between water pressure and power on MRR.

Figure 9 shows statistical histogram of AGV for finish cutting. It can be seen from Fig. 9 that the mean of AGV is $53.49 \mathrm{~V}$. Most of the AGV exist between 48 and $64 \mathrm{~V}$. It can be concluded that the status of the cutting is normal in whole. AGV is close to the arc discharge voltage in no. 13
Fig. 10 Comparison chart of relatively main factor effects on $\mathrm{Ra}$ between rough and finish cutting

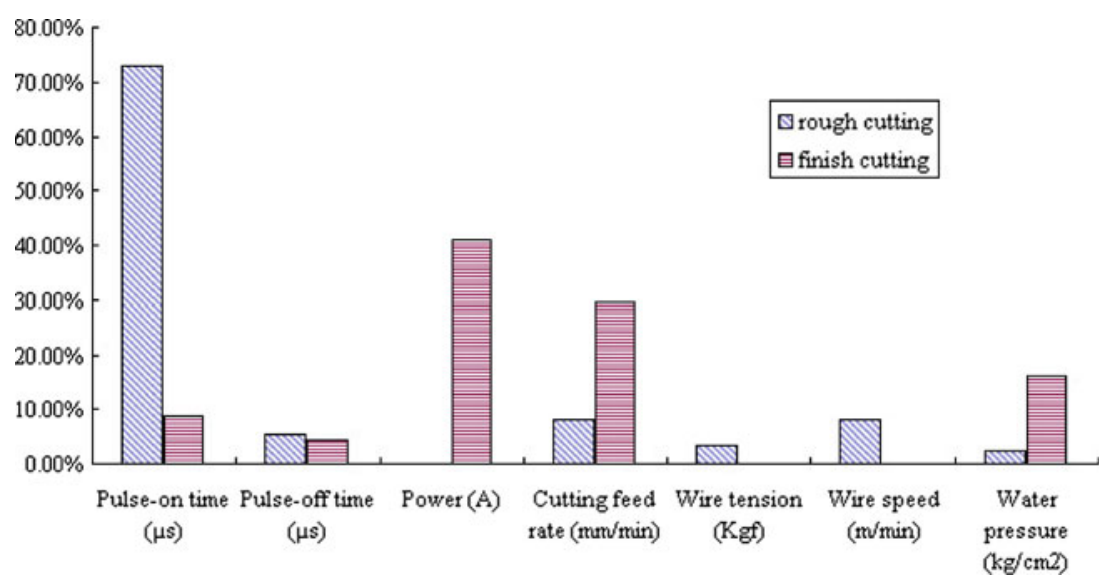


Fig. 11 Comparison chart of relatively main factor effects on MRR between rough and finish cutting

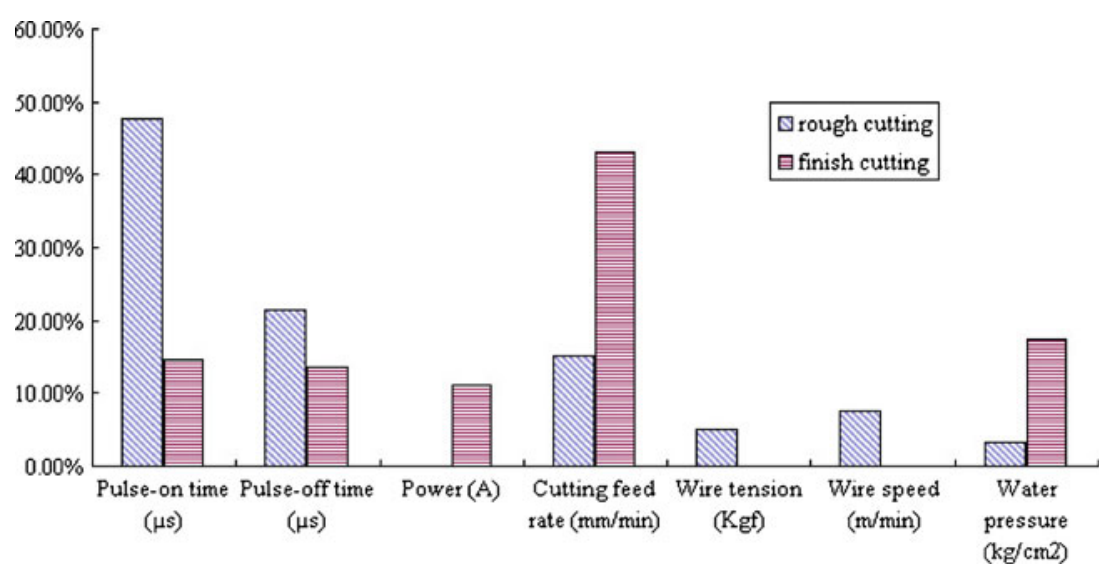

experiment (in Table 5). In this experiment, there is a phenomenon of the feedback of wire. Therefore, this reduces the MRR, and also increases the Ra.

\subsection{Comparative analysis between rough cutting and finish cutting}

In this section, comparative analysis between rough cutting and finish cutting on Ra and MRR is drawn. Figure 10 depicts the chart of relatively main factor effects on $\mathrm{Ra}$ between rough cutting and finish cutting. The data of Fig. 10 come from Tables 6 and 8. It can be seen from Fig. 10 that there are significant differences in the influence of some factors on Ra. The relatively main factor effects of cutting feed rate and water pressure are not significant on $\mathrm{Ra}$ for rough cutting, and the main relatively factor effect of $\mathrm{Ra}$ depends on pulse-on time in rough cutting. Therefore, it can be drawn that the discharge parameters have the significant effect on $\mathrm{Ra}$ on rough cutting. However, the

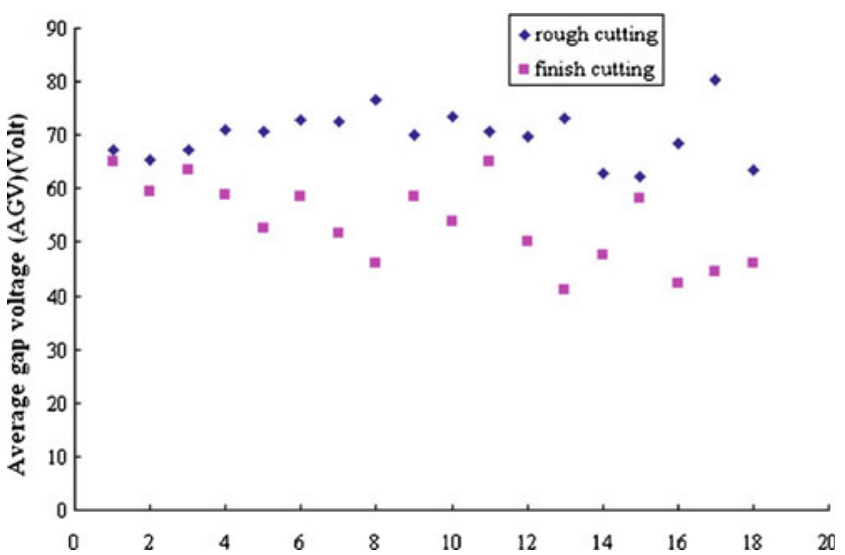

Fig. 12 Scatter plot of AGV on rough and finish cutting effect of cutting feed and water pressure cannot be ignored on Ra on finish cutting, because the lower of cutting feed rate and higher water pressure can significantly improve the processing conditions. Therefore, the auxiliary processing conditions should be taken seriously on $\mathrm{Ra}$ on finish cutting.

The same procedure is used for MRR. Figure 11 depicts the chart of relatively main factor effects on MRR between rough cutting and finish cutting. The data of Fig. 11 come from Tables 7 and 8. On both rough and finish cutting, the discharge parameters have significant effect on MRR. It also can be drawn from Fig. 11 that there are significant differences in the influence of some factors on Ra. Both cutting feed rate and water pressure have few effects on $\mathrm{Ra}$ on rough and finish cutting, but the effects cannot be ignored on finish cutting. It is also because the lower cutting feed rate and higher water pressure can significantly improve the processing conditions. Therefore, the auxiliary processing conditions should be taken seriously on MRR on finish cutting.

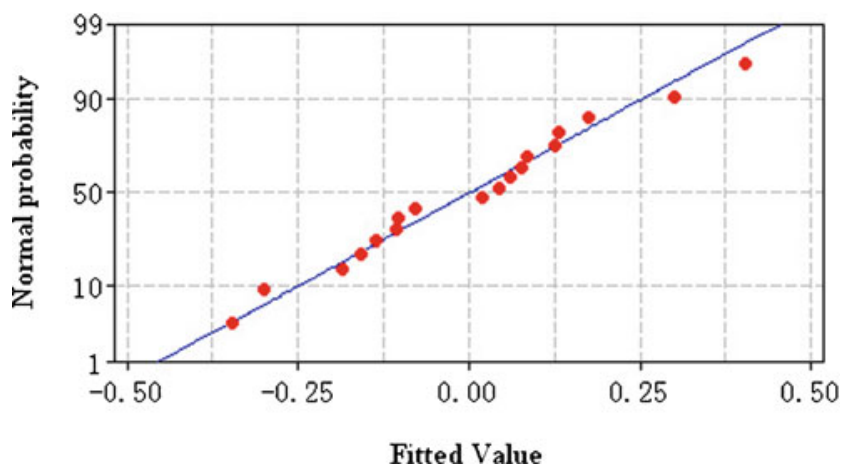

Fig. 13 Normal probability plots of residuals of MRR (in square millimeter per minute) on rough cutting 


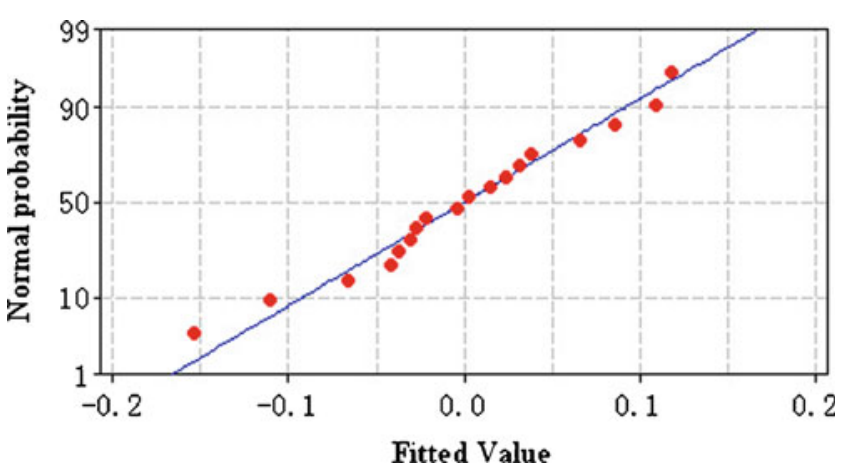

Fig. 14 Normal probability plots of residuals of $\mathrm{Ra}$ (in micrometers) on finish cutting

Figure 12 draws the scatter plot of AGV on rough and finish cutting. Generally speaking, the AGV of finish cutting is lower than that of rough cutting. In Section 4.2, AGV is the intimation of status of processing, and low voltage shows the unstable status of processing. In addition, the change amplitude of AGV is relatively large in the whole finish cutting experiments. Therefore, the processing conditions on finish cutting are not good and the auxiliary processing conditions should be improved in finish cutting. Then, a good Ra will be obtained under optimized parameters. High AGV means lower utilization for WEDM. Therefore, in order to increase MRR, cutting parameters should be optimized on rough cutting.

\section{Regression model and analysis}

MRR is a goal to be pursued to maximize under suitable Ra on rough cutting, and $\mathrm{Ra}$ is a goal to be pursued to minimize under suitable MRR on finish cutting. Equations 4 and 5 presents the relationship of between cutting parameters and MRR and Ra by generalized regression analysis on rough and finish cutting, respectively, where P.O. is the plus-on time, P.F. is the plus-off time, C.F. is the cutting feed rate, W.T. is the wire tension, W.S. is the wire speed, and W.P. is the water pressure. Since the $F$ value (in Table 11) will be more than 0.05 , the other interaction items in Eq. 3 are removed, excluding that between the P.O. and the P.F. To check whether the fitted model describe the experimental

Table 10 ANOVA on MRR regression analysis

\begin{tabular}{|c|c|c|c|c|c|}
\hline Source & $\mathrm{DF}$ & $\mathrm{SS}$ & MS & $F$ & $P$ \\
\hline Regression & 8 & 16.8167 & 2.4024 & 36.9603 & 0.001 \\
\hline Residual error & 9 & 0.65 & 0.072 & & \\
\hline Total & 17 & 17.4665 & & & \\
\hline
\end{tabular}

Table 11 ANOVA on Ra regression analysis

\begin{tabular}{lrllll}
\hline Source & DF & SS & MS & $F$ & $P$ \\
\hline Regression & 6 & 0.1489 & 0.0248 & 3.1739 & 0.0465 \\
Residual error & 11 & 0.086 & 0.0078 & & \\
Total & 17 & 0.2349 & & & \\
\hline
\end{tabular}

Table $12 \eta$ value of MRR (in square millimeter per minute) on rough cutting

\begin{tabular}{lllllll}
\hline $\begin{array}{l}\text { Level } \\
\text { time }\end{array}$ & $\begin{array}{l}\text { Pulse-on } \\
\text { time }\end{array}$ & $\begin{array}{l}\text { Pulse-off } \\
\text { feed rate }\end{array}$ & $\begin{array}{l}\text { Wire } \\
\text { tension }\end{array}$ & $\begin{array}{l}\text { Wire } \\
\text { speed }\end{array}$ & $\begin{array}{l}\text { Water } \\
\text { pressure }\end{array}$ \\
\hline 1 & -144.88 & -5.35 & -36.65 & -36.20 & -35.79 & -51.68 \\
2 & -9.58 & -25.29 & -51.86 & -39.79 & -39.35 & -69.51 \\
3 & 33.27 & -90.55 & -32.68 & -45.20 & -46.06 & \\
Delta & 178.15 & 85.2 & 19.18 & 9 & 10.27 & 17.83 \\
\hline
\end{tabular}

Table $13 \eta$ value of Ra (in micrometers) on finish cutting

\begin{tabular}{lccccc}
\hline Level & $\begin{array}{l}\text { Pulse-on } \\
\text { time }\end{array}$ & $\begin{array}{l}\text { Pulse-off } \\
\text { time }\end{array}$ & Power & $\begin{array}{l}\text { Cutting } \\
\text { feed rate }\end{array}$ & $\begin{array}{l}\text { Water } \\
\text { pressure }\end{array}$ \\
\hline 1 & 55.48 & 52.89 & 37.95 & 65.19 & 71.32 \\
2 & 55.44 & 56.79 & 65.10 & 52.11 & 92.01 \\
3 & 52.41 & 53.65 & 60.28 & 46.03 & \\
Delta & 3.07 & 3.9 & 27.15 & 19.16 & 20.69 \\
\hline
\end{tabular}

Table 14 Optimal setting for MRR (in square millimeter per minute) on rough cutting

\begin{tabular}{lllllll}
\hline Level & $\begin{array}{l}\text { Pulse-on } \\
\text { time }\end{array}$ & $\begin{array}{l}\text { Pulse-off } \\
\text { time }\end{array}$ & $\begin{array}{l}\text { Cutting } \\
\text { feed rate }\end{array}$ & $\begin{array}{l}\text { Wire } \\
\text { tension }\end{array}$ & $\begin{array}{l}\text { Wire } \\
\text { speed }\end{array}$ & $\begin{array}{l}\text { Water } \\
\text { pressure }\end{array}$ \\
\hline $\begin{array}{l}\text { Level } \\
\text { number }\end{array}$ & 3 & 1 & 3 & 1 & 1 & 1 \\
$\begin{array}{l}\text { Factor } \\
\text { magnitude }\end{array}$ & 13 & 10 & 4 & 6 & 3 & 5 \\
\hline
\end{tabular}

Table 15 Optimal setting for Ra (in micrometers) on finish cutting

\begin{tabular}{llllll}
\hline Level & $\begin{array}{l}\text { Pulse-on } \\
\text { time }\end{array}$ & $\begin{array}{l}\text { Pulse-off } \\
\text { time }\end{array}$ & Power & $\begin{array}{l}\text { Cutting } \\
\text { feed rate }\end{array}$ & $\begin{array}{l}\text { Water } \\
\text { pressure }\end{array}$ \\
\hline Level number & 1 & 2 & 2 & 1 & 2 \\
Factor magnitude & 5 & 5 & 3 & 0.3 & 6 \\
\hline
\end{tabular}


Table 16 Results of the experimental confirmation for MRR (in square millimeter per minute) on rough cutting

\begin{tabular}{llll}
\hline Initial cutting parameters & & Optimal cutting parameters \\
\cline { 3 - 4 } & & Prediction & Experiment \\
\hline Level & A2B2C2D2E2F2 & A3B1C3D1E1F1 & A3B1C3D1E1F1 \\
MRR $\left(\mathrm{mm}^{2} / \mathrm{min}\right)$ & 1.38 & 3.06 & 3.16 \\
$\mathrm{~S} / \mathrm{N}$ ratio $(\mathrm{dB})$ & 2.78 & 9.71 & 9.99 \\
\hline
\end{tabular}

data, the multiple regression coefficients $\left(R^{2}\right)$ were computed. The more $R^{2}$ approaches unity, the better the model fits the experimental data. The multiple regression coefficients for MRR and Ra were found to be 0.9628 and 0.7513 , respectively.

$$
\begin{aligned}
\text { MRR }= & -0.8323+0.317232 \text { P.O. }+0.00601824 \text { P.F. } \\
& +0.119053 \text { C.F. }-0.00952702 \text { W.T. } \\
& +0.040395 \text { W.S. }-0.0276495 \text { W.P. } \\
& -0.0054224 \text { P.O. } \times \text { P.F. } \\
& +0.0004501 \text { W.P. } \times \text { W.T. }
\end{aligned}
$$

$$
\begin{aligned}
\mathrm{Ra}= & 0.441799+0.00938377 \text { P.O. } \\
& +0.0110088 \text { P.F. }-0.0410493 \text { Power } \\
& +0.211858 \text { C.F. }-0.0356111 \text { W.T. } \\
& -0.00100247 \text { P.O. } \times \text { P.F. }
\end{aligned}
$$

The normal probability plot of residuals on MRR is displayed in Fig. 13. A normal probability plot is just a graph of the cumulative distribution of the residuals on normal probability paper with the ordinate scaled so that the normal distribution is plotted as a straight line. Figure 14 shows the normal probability plot of residuals on Ra. It can be seen that the error normality of both MRR and Ra are considered to be valid.

ANOVA is utilized for regression analysis and its analysis is listed in Tables 10 and 11, respectively. The $p$ value shows that the estimated models by generalized regression analysis are significant at the $\alpha$-level of 0.05 in both Tables 10 and 11. The above regression models for MRR and $\mathrm{Ra}$ in WEDM are of great importance for the proper selection of cutting conditions during the cutting of tool steel YG15.

\section{$6 \mathrm{~S} / \mathrm{N}$ ratio analysis}

The characteristic that larger value represents better machining performance, such as MRR, is called 'the-larger-thebetter, LB'. Inversely, the characteristic that smaller value represents better machining performance, such as surface roughness, is called 'the-smaller-the-better, SB' [24]. In quality engineering, the $\mathrm{S} / \mathrm{N}$ ratio could be an effective utilization to obtain the significant parameter from those controlling cutting parameters by evaluating the minimum variance. For $\mathrm{LB}$ and $\mathrm{SB}$, the definitions of the $\mathrm{S} / \mathrm{N}$ ratio are listed in Eqs. 3 and 7, in which $\eta$ is the $\mathrm{S} / \mathrm{N}$ ration, $y_{i}$ is the response, and $n$ is the number of replications.

$L B, \eta=-10 \times \log \left[\frac{1}{n} \sum_{i=1}^{n} \frac{1}{y_{i}^{2}}\right]$

$S B, \eta=-10 \times \log \left[\frac{1}{n} \sum_{i=1}^{n} y_{i}^{2}\right]$

The $\eta$ value of MRR on rough cutting and of Ra on finish cutting are presented in Tables 12 and 13, respectively. The largest value of $\eta$ depicts the optimal condition. The optimal settings for MRR on rough cutting and for Ra on finish cutting are listed in Tables 14 and 15, respectively.

Table 17 Results of the experimental confirmation for Ra (in micrometers) on finish cutting

\begin{tabular}{llll}
\hline Initial cutting parameters & & \multicolumn{2}{l}{ Optimal cutting parameters } \\
\cline { 3 - 4 } & & Prediction & Experiment \\
\hline Level & A2B2C2D2E2 & A1B2C2D1E2 & A1B2C2D1E2 \\
Surface roughness $(\mathrm{Ra})(\mu \mathrm{m})$ & 0.31 & 0.25 & 0.22 \\
S/N ratio $(\mathrm{dB})$ & 10.17 & 12.04 & 13.15 \\
\hline
\end{tabular}




\section{Confirmation experiments}

The confirmation experiment is the final step in the DOE process. The purpose of the confirmation experiment is to validate the conclusions which are drawn from the analysis phase. The confirmation experiment is performed under a specific combination of the factors and levels which is previously evaluated. In this research, after determining the optimization of cutting conditions by $\mathrm{S} / \mathrm{N}$ ratio analysis and predicting the response under these conditions by regression model, new experiments are designed and conducted with these conditions.

The next step is to predict and verify the improvement of the performance characteristics. The predicted S/N ratio $\left(\eta_{o p t}\right)$ which is obtained under the optimal levels of cutting parameters can be calculated as Eq. 8:

$\eta_{o p t}=\eta_{m}+\sum_{j=1}^{k} \eta_{j}-\eta_{m}$

where $\left(\eta_{m}\right)$ is total mean of the $\mathrm{S} / \mathrm{N}$ ratios, $\left(\eta_{j}\right)$ is mean $\mathrm{S} / \mathrm{N}$ ratio at the optimum levels, and $k$ is number of main design parameters that affect the quality characteristics.

The results of the experimental confirmation under the optimal levels of cutting parameters are listed in Tables 16 and 17. Table 16 shows the comparison of the predicted MRR with the actual MRR under the optimal levels of cutting parameters on rough cutting. The improvement in $\mathrm{S} / \mathrm{N}$ ratio from the initial cutting parameters to the level of optimal cutting parameters is $7.21 \mathrm{~dB}$. The MRR is increased by 2.23 times. Therefore, the MRR on rough cutting is greatly improved by using the statistical analyses in this research. Table 17 shows the comparison of the predicted Ra with the actual Ra under the optimal levels of cutting parameters on finishing cutting. The improvement in $\mathrm{S} / \mathrm{N}$ ratio from the initial cutting parameters to the level of optimal cutting parameters is $2.98 \mathrm{~dB}$. The Ra is decreased by 1.41 times. The experimental results confirm the validity of the utilized statistical analyses for improving the cutting performance and optimizing the cutting parameters. Therefore, the MRR on rough cutting and Ra on finish cutting can be greatly improved by applying the method.

\section{Discussion}

WEDM is a thermal process. The mechanical, metallurgical, topological, and chemical condition of the surface region are described in the surface integrity. Except main effect of process parameters, there is interaction effect of them. The trend of them on MRR and Ra is very different, which indicates that the thermal process of WEDM is more complicated.
The MRR and Ra of WEDM is related to the material removal per discharge, which is determined by the pulse energy per discharge. The pulse energy per discharge can be expressed as Eq. 9, which follows:

$E=\int_{0}^{t_{0}} u(t) i(t) d t$

where $t_{0}$ is the discharge duration, $u(t)$ is the discharge voltage, $i(t)$ is the discharge current, and $E$ is the pulse energy per discharge. Since the discharge voltage $u(t)$ keeps constant during the discharge, the pulse energy per discharge is determined by the pulse duration $t_{0}$ and discharge current $i(t)$, which is determined by pulse-on time in the WEDM.

By molecular dynamics simulation of the material removal mechanism [1], it is found that higher power densities result in larger diameter and depth of the melted area as well as higher metal removal efficiency. The change in the metal removal efficiency is similar to that in the depth of the melted area, indicating that the depth of the melted area has more significant effects on the metal removal efficiency. This can be confirmed by Fig. 15. This figure draws some SEM pictures of WEDM workpiece of experiment. It can be drawn from Fig. 15 that the diameter of crater on rough cutting is larger than that on finish cutting.

It can be concluded from the above discussion that pulseon time has the extremely important effect on MRR for rough cutting, since the current cannot be set on this cutting condition. MRR is directly proportional to the power supplied during this pulse-on time. As the pulse-off time is decreased, more sparks will be generated. Therefore, this leads to improvement in MRR.

On finish cutting, power and cutting feed rate have the extremely important effect on Ra. Except discharge parameters, the parameters of cutting condition cannot be ignored, especially cutting feed rate. The cutting feed rate is lower, and the gap of discharge could remain more constant; the water pressure is higher, and more powder of cutting is flushed by it. Therefore, the lower cutting feed rate and higher water pressure can improve the cutting conditions, and then the Ra will be better.

However, there are some crackers in the surface of workpieces both on the rough cutting and finish cutting, which can be drawn from SEM (see Fig. 15). As depicted by Table 1, the hardness of tool steel YG15 is large. Then, it is more difficult to cut this steel by WEDM. The number of cracker on finish cutting is more than that on rough cutting. Too long machine time might be due to excessive heat focusing on the same microstructure. Therefore, more thermal stress leads to be cracker on the surface of workpieces. 
Fig. 15 SEM pictures of WEDM workpiece: (a) experiment no. 11 on first rough cutting; (b) experiment no. 12 on second rough cutting; (c) experiment no. 3 on first finish cutting; (d) experiment no. 9 on second finish cutting
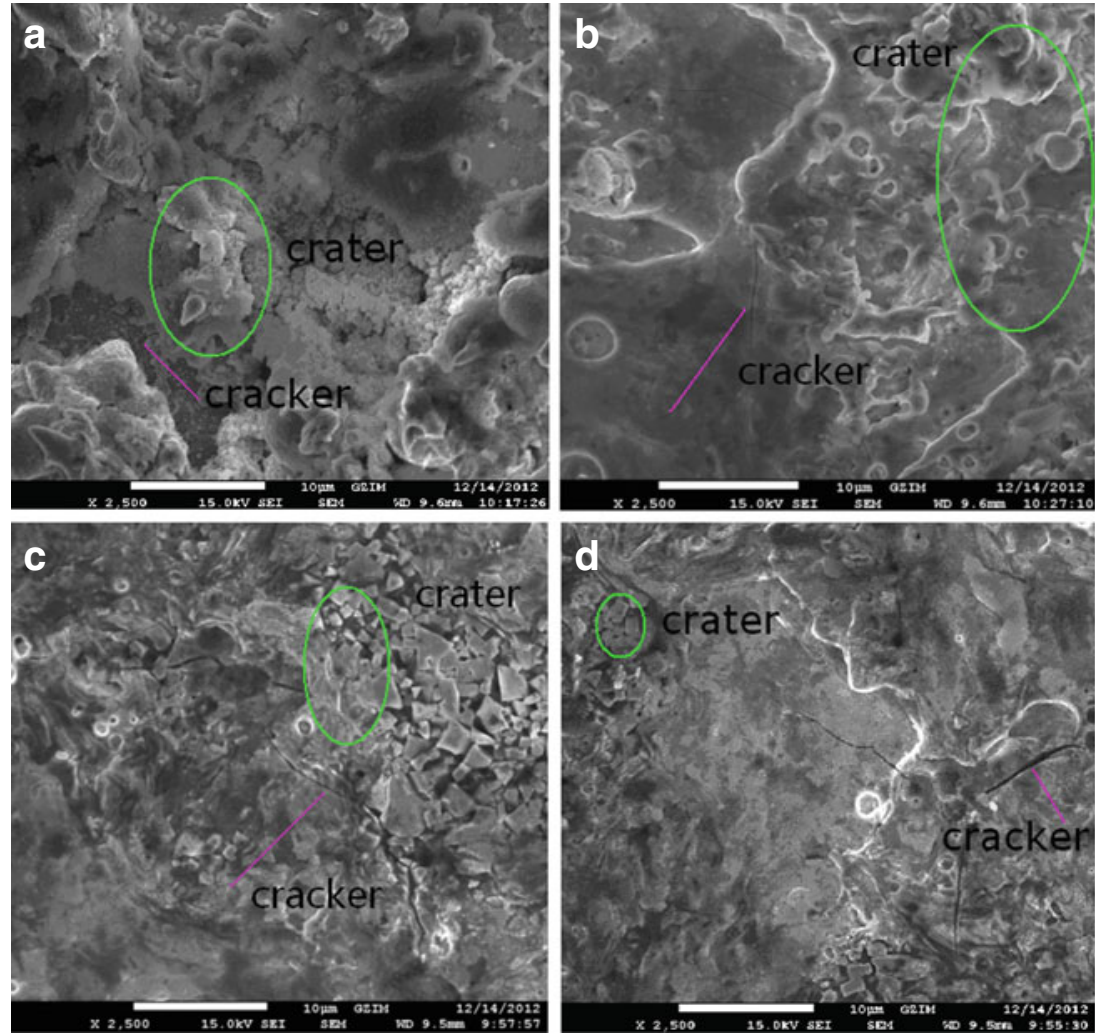

\section{Conclusion and future work}

The effects of cutting parameters on Ra, MRR, and AGV in the WEDM of high hardness tool steel YG15 are experimentally investigated for both rough cutting and finish cutting. The following conclusions are drawn from the above investigation.

1. On rough cutting, pulse-on time has the extremely important effect on $\mathrm{Ra}$, and the effects of pulse-on time, pulse-off time, and cutting feed rate are more important than wire tension, wire speed, and water pressure on MRR. In addition, there are some interaction effects both on Ra and MRR.

2. On finish cutting, power and cutting feed rate have the extremely important effect on $\mathrm{Ra}$; and pulse-on time, cutting feed rate, and water pressure are more important than other factors on MRR. Similarly, there are some interaction effects both on Ra and MRR.

3. The auxiliary processing conditions should be taken in account both on Ra and MRR on the finish cutting.

4. The ANOVA for regression analysis indicates that the estimated model for MRR on rough cutting and for Ra on finish cutting are significant.

5. The confirmation experiments show that it is possible to increase the MRR and decrease the Ra significantly by using the proposed statistical technique. The MRR is increased by 2.23 times and $\mathrm{Ra}$ is decreased by 1.41 times.

In future work, the relationship of cutting conditions and surface crack formation, such as whiter layer, crack and micro-surface topography, will be investigated. In addition, one CAPP system which guides process in order to optimize cutting conditions will be build in the WEDM.

Acknowledgments This research is supported by the National Natural Science Foundation of China under grant nos. 51175207 and 51121002. In addition, the authors would like to thank Mr. L. Shengjun, from Dongguan Hustinova Precision Machinery Co., Ltd., for the experimental tests used in this project.

Open Access This article is distributed under the terms of the Creative Commons Attribution License which permits any use, distribution, and reproduction in any medium, provided the original author(s) and the source are credited.

\section{References}

1. Yang XD, Guo JW, Chen XF, Kunieda M (2011) Molecular dynamics simulation of the material removal mechanism in microEDM. Precis Eng 35:51-57

2. Kao JY, Tsao CC, Wang SS, Hsu CY (2010) Optimization of the EDM parameters on machining Ti-6Al-4V with multiple quality characteristics. Int J Adv Manuf Technol 47:395-402 
3. Habib MA, Rahman M (2010) Performance analysis of EDM electrode fabricated by localized electrochemical deposition for micro-machining of stainless steel. Int J Adv Manuf Technol 49:975-986

4. Villeneuve LF, Curodeau A (2013) Dry die-sinking EDM with mouldable graphiteCpolymer electrode investigation of process parameters and pulse identification methods. Int J Adv Manuf Technol 65:1125-1139

5. Suganthi $\mathrm{XH}$, Natarajan U, Sathiyamurthy S, Chidambaram $\mathrm{K}$ (2013) Prediction of quality responses in micro-EDM process using an adaptive neuro-fuzzy inference system (ANFIS) model. Int J Adv Manuf Technol. doi:10.1007/s00170-0134731-5

6. Brown J (1998) Advanced machining technology handbook. McGraw-Hill, New York

7. Jun QU, Shin AJ, Scattergood RrO (2002) Development of the cylindrical wire electrical discharge machining process, part 2: surface integrity and roundness. ASME J Manuf Sci Eng 124:708714

8. Gokler MI, Ozanozgu AM (2000) Experimental investigation of effects of cutting parameters on surface roughness in the WEDM process. Int J Mach Tools Manufac 40:1831-1848

9. Liao YS, Woo JC (1997) The effects of machining settings on the behavior of pulse trains in the WEDM process. J Mater Process Technol 71:433-439

10. Gatto A, Iuliano L (1997) Cutting mechanisms and surface features of WEDM machined metal matrix composites. J Mater Process Technol 65:209-214

11. Manna A, Bhattacharyya B (2005) Taguchi and Gauss elimination method: a dual response approach for parametric optimization of CNC wire cut EDM of PRAlSiCMMC. Int J Adv Manuf Technol 28:67-75

12. Ramakrishnan R, Karunamoorthy L (2004) Surface roughness model for CNC wire electro discharge machining. J Manuf Techol Today 3(5):8-11
13. Kung KY, Chiang KT (2008) Modeling and analysis of machinability evaluation in the wire electrical discharge machining (WEDM) process of aluminum oxide-based ceramic. J Mater Manufact Proc 23:241-250

14. Ramakrishnan R, Karunamoorthy L (2005) Multi response optimization of wire EDM operations using robust design of experiments. Int J Adv Manuf Technol 29:105-112

15. Mohammadi A, Tehrani AF, Emania E, Karimi D (2008) Statistical analysis of wire electrical discharge turning on material removal rate. J Mater Process Technol 205:283-289

16. Aminollah M, Alireza FT, Emanian E, Karimi D (2008) A new approach to surface roughness and roundness improvement in wire electrical discharge turning based on statistical analyses. Int J Adv Manuf Technol 39:64-73

17. Patowari PK, Saha P, Mishr PK (2011) Taguchi analysis of surface modification technique using $\mathrm{W}-\mathrm{Cu}$ powder metallurgy sintered tools in EDM and characterization of the deposited layer. Int J Adv Manuf Technol 54:593-04

18. Assarzadeh S, Ghoreishi M (2008) Neural-network-based modeling and optimization of the electro-discharge machining process. Int J Adv Manuf Technol 39:488-500

19. Patowari PK, Saha P, Mishra PK (2010) Artificial neural network model in surface modification by EDM using tungsten-copper powder metallurgy sintered electrodes. Int J Adv Manuf Technol 51:627-638

20. Ross PJ (1988) Taguchi techniques for quality engineering. McGraw Hill, New York

21. Mori T (1991) The new experimental design: Taguchi's approach to quality engineering. ASI press, Dearborn

22. Mason RL, Gunt RF, Hess JL (2003) Statistical design and analysis of experiments. Wiley, New York

23. Phadke MS (1989) Quality engineering using robust design. Prentice-Hall, Englewood Cliffs

24. Hicks CR, Turner KV (1999) Fundamental concepts and the design of experiments. Oxford University Press, New York 